\title{
Calibration process for groundwater flow model of a river influenced shallow aquifer
}

\author{
Andrea Kolencsik-Tóth*, Balázs Kovács \\ University of Miskolc, Institute of Environmental Management, Miskolc, Hungary
}

Received: January 28, 2015; accepted: January 28, 2015

\begin{abstract}
Understanding and simulating the interaction of groundwater and surface water is essential to hydrologists. Water supply and water quality aspects are a few examples of common water-resource issues where understanding the interconnections of groundwater and surface water is fundamental to develop an effective water-resource management and policy. In our study a detailed investigation of a riverbank aquifer was performed to be able to simulate and predict the behavior of the flow system. The continuous hydraulic head measurements in the area of interest showed strong influence on the hydraulic head field caused by intensively changing river head at a distance from the river up to 3,500 $\mathrm{m}$. Based on the results steady state and transient flow calculations were compared, and a great effort has been made to ensure that the model more precisely describe the time and space variable flow field. Beside fulfilling the standard calibration requirements, a multi-step calibration process was performed.
\end{abstract}

Keywords: groundwater, surface water, interaction, flow model, model calibration

\section{Introduction}

Research in the sustainable management of coupled groundwater-surface water (GW-SW) resources has grown steadily over the last years. Surface and groundwater interaction is widely investigated, but in most cases only from a groundwater supply aspect, with the goal of using bank-filtered groundwater. Since the aim is to provide as high production rates as possible the wells are established along the riverside, and the main task of hydrogeologic investigations is to accurately determine the strengths

\footnotetext{
* Corresponding author: Egyetem út, H-3515 Miskolc, Hungary;

E-mail: hgandi@uni-miskolc.hu
} 
of hydraulic interaction between the surface water and the groundwater body through the leaky clogged zone of the aquifer. However, examining the effect of surface water on shallow aquifers in the zones behind the productive area should be also in the focus of investigations. There are several potentially or actually contaminated industrial sites located on riverbanks in Hungary impacted by surface water, and the transport of different contaminants in this kind of environment is very dependent on the actual state of the flow system. In some sites where this is the case, groundwater can be a major and potentially long-term contributor to contamination of surface water.

\section{The investigated area}

The site of interest is located in NE Hungary at riverside of the Tisza River in central Hungary (Fig. 1). The area is of high economic interest due to the industrial zone located about 2,500 $\mathrm{m}$ to the west of the river. From a geologic point of view the 20 m-thick shallow aquifer is part of an alluvial fan, and consists of highly permeable gravelly formations. The gravel layer is divided vertically into two parts by a silty, semi-permeable zone in the 12-16 m depth interval. This dividing layer is absent in the central part of the investigated area. Below the formations of the alluvial fan's deposits, sandy layers used for public and industrial water supply are located.

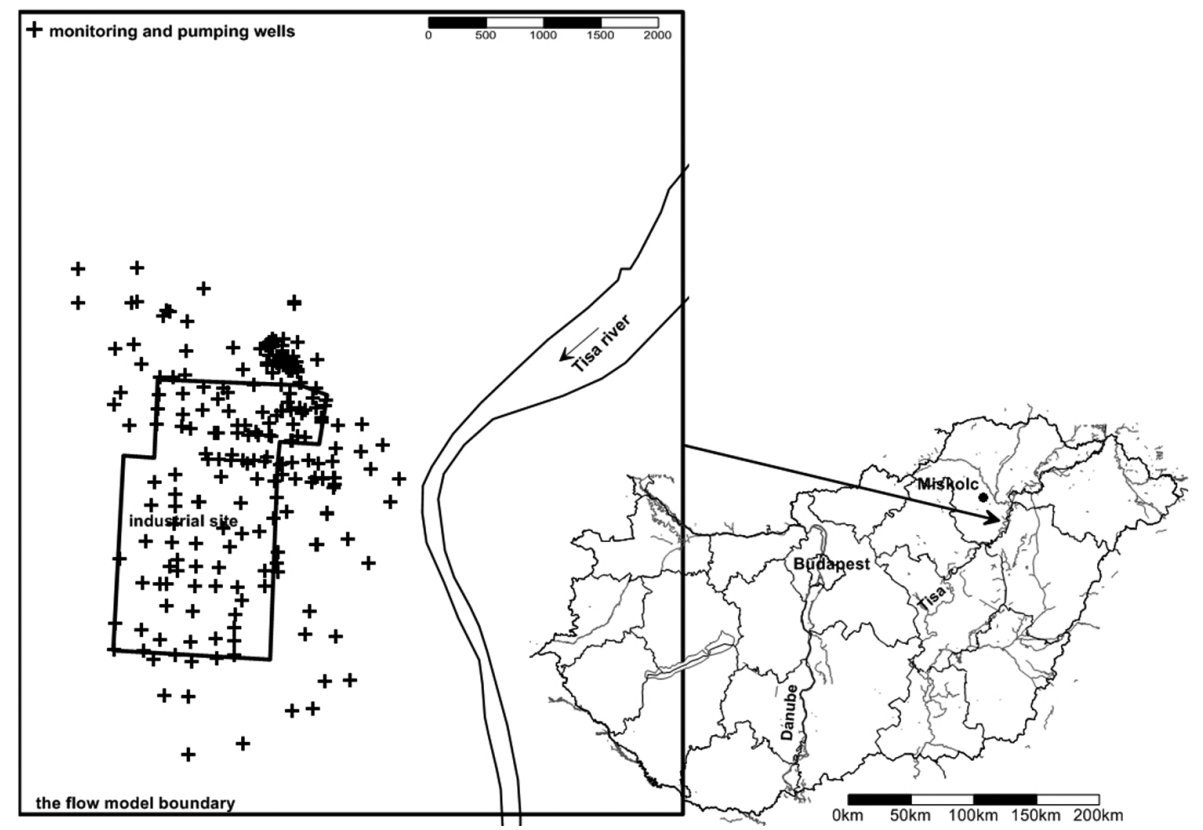

Fig. 1

Generalized map of the investigated site 
During the site investigation a large monitoring system was established and pumping tests and long-term hydraulic head measurements were carried out. The over 100 wells are open to both on the upper and lower parts of the formations of the alluvial fan; only a few wells were drilled to monitor the underlying drinking water aquifers. The system gave us enough information to accurately describe the regime of GWSW interaction within a distance from the river of up to $3,000 \mathrm{~m}$.

Based on the evaluation of over 80 pumping tests (GÁMA-GEO 2008) performed on the monitoring wells of the sites, the hydraulic conductivity of the alluvial sediments is in the $2.3 \times 10^{-4}-9.3 \times 10^{-4} \mathrm{~m} / \mathrm{s}$ range and the underlying sandy aquifer is less permeable. The vertical hydraulic conductivity is $2.3 \times 10^{-5}-9.3 \times 10^{-5} \mathrm{~m} / \mathrm{s}$ in the aquifers and $1 \times 10^{-8} \mathrm{~m} / \mathrm{s}$ in the aquitards. The direction of the regional groundwater flow is from NW-W to SE-E due to the dominantly discharging Tisza River.

\section{The monitoring results}

Over 30 dataloggers were installed within an approx. $20 \mathrm{~km}^{2}$ area of interest to continuously record groundwater level caused by the fluctuation of the river level. There are over 4 years of continuous monitoring results recorded up to now. Fortunately this period of investigation includes dry, average hydrological years as well as the year 2010 with extremely high precipitation. The given meteorological conditions permitted investigating the site both at low and high groundwater levels; meanwhile, the other two years were considered to show average flow conditions.

Based on the long-term groundwater monitoring data of the site a strong effect of the fluctuating river level was tracked in the hydraulic head field. The effect of even a short flood period was already detected both in the shallow and the deeper part of
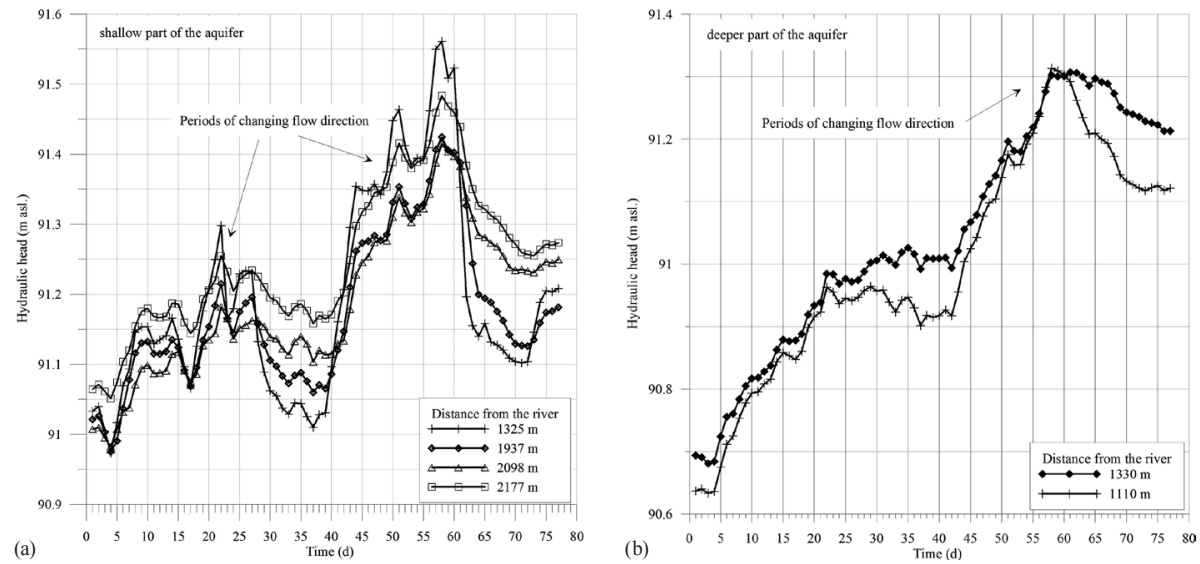

Fig. 2

Measured groundwater level time series in shallow (a) and in deeper (b) part of the aquifer 
the aquifer, even at more than 2,500 $\mathrm{m}$ distance. Despite the fact that previously all experts described a permanent discharge by the river and some small effects within only a few tens of meters from the river, the measurements detected river-originated recharge in large areas along the riverside. In flood periods, in addition to surface water entering the aquifer, the flow directions and gradient of the flow field do not only change within a narrow zone along the shoreline. Up to a certain distance (a maximum of 1,200-1,400 m) from the river, the flow turns to the opposite direction. This is very important since the contamination is partially in the riverhead-affected area; therefore this may not only modify the seepage velocities but also the contaminant fluxes.

In Fig. 2 the time series of a few monitoring points are presented, in which the phenomena of turning flow directions can be demonstrated. The wells are established along a line perpendicular to the river, and during the measurement time period a $2.5 \mathrm{~m}$ elevation was recorded in the river level.

\section{Steady-state and transient flow model}

Based on the hydrogeologic information gleaned from field measurements groundwater flow modeling activities were initiated. In the first step, based on the accurate geologic structure and the head field obtained from the detailed site investigation, a steady-state flow model was created.

The model was built using Processing MODFLOW v7 and v8 (Chiang 2006; Chiang 2010). The model domain of $5800 \times 7000 \mathrm{~m}$ was built up from elements of 5-20 m $\times 5-20 \mathrm{~m}$. The vertical discretization was solved using 10 layers, of which the upper 4 represented the alluvial fan sediments and the lower ones modeled the drinking water aquifers and the aquitards between them. The layers of the shallow and deep part of the fan were simulated using hydraulic conductivity distributions collected from the many available pumping test results. The lower aquifers, for their part, were considered to be homogeneous.

With the steady-state model an average state of the flow system was simulated based on the results of simultaneously recorded groundwater level data at the monitoring wells through time. The direction of the regional groundwater flow is from NW-W to SE-E during average conditions, with discharge into the Tisza River, which was included in the model as a permanent boundary condition.

For further investigation the use of a very detailed transient flow model of the site was necessary, because neither the hydrodynamics of the groundwater flow nor the movement of the contaminant plume can be simulated and precisely predicted with a permanent simulation. The transient model has a very high time resolution with 5-10 day-long periods; the total simulated time is 30 years.

More than 30 years of river level data - measured at the gauging stations of the Tisza River upstream and downstream of the site of interest - were analyzed statistically to filter out the most relevant years of different meteorological conditions. 

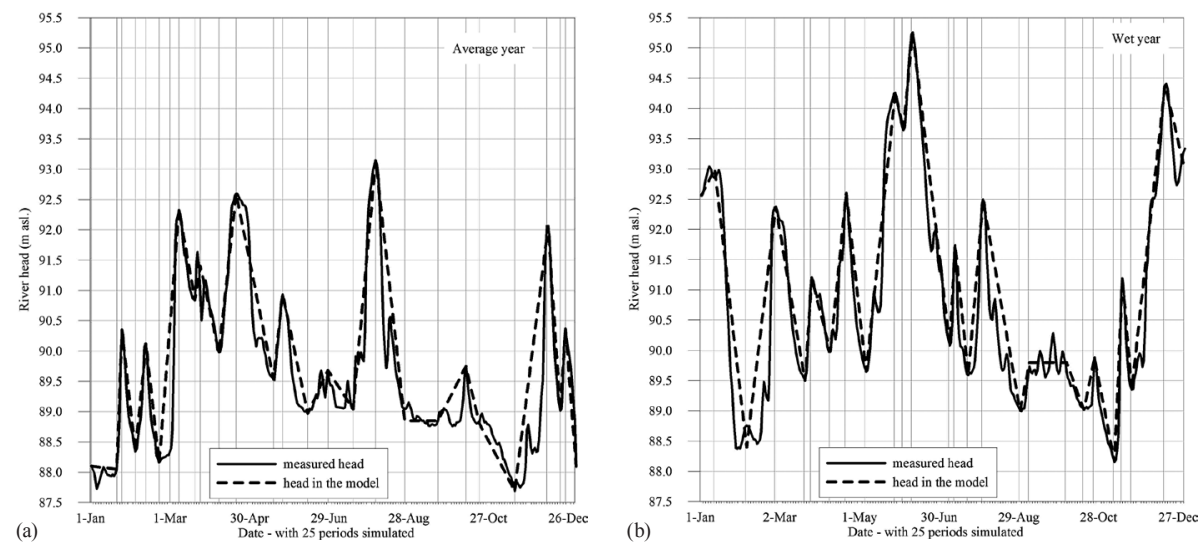

Fig. 3

The model adoption of river level changing for an average (a) and for a wet (b) year

Precipitation and agricultural aridity data were also examined to create the right cycle of changing hydrometeorological conditions. The level fluctuations of the Tisza River were simplified and then built into the model using a river and also a time-variant head boundary package, in order to continuously change the river heads during the simulation. In Fig. 3 the measured river levels and applied characteristics in the model are summarized for an average and for a wet year.

\section{Calibration of the flow model}

Flow-model calibration is a continuously evolving research topic in hydrogeology. Researchers put in much effort to make the models more realistic, in order to accurately describe the true hydrodynamic processes. The direction of improvements in model calibration issues are the so-called inverse modeling and inverse calibration processes. Marsily at al. (2000) present an outstanding review about the inverse problems in hydrogeology, and Carrera and Neuman (1986a, b, and c) offer a very effective summary of the standard inverse techniques available in groundwater modeling; further work insures making the inverse algorithms a routine approach for practitioners (Poeter and Hill 1997; Hill 1998; Hill et al. 2000; Walter and LeBlanc 2008). The match of calculated and measured head data are commonly used as an indicator of the model accuracy. In the steady-state case the simultaneously recorded head in the observation points is used, while in the transient case the fitting error of measured and calculated head time series is the relevant parameter of the calibration.

Calibration of the steady-state model was performed with a standard trial-end-error process using the observed and calculated head data. During the process the hy- 


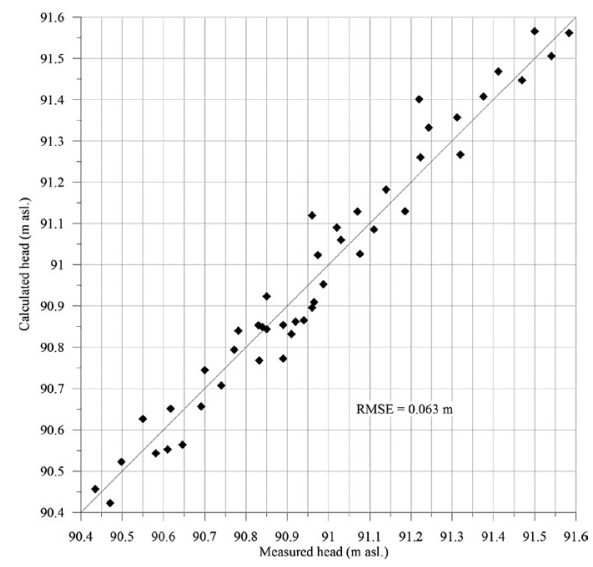

Fig. 4

Measured and calibrated calculated head

draulic conductivity values of the model layers were changed until they reached the required value of Root Mean Square Error (RMSE), which was defined as 10 $\mathrm{cm}$. More than 10 distributions of hydraulic conductivity of the gravel layers were created based on the pumping test results, and these were applied to the calibration. After filtering the monitoring wells for outlier head records, the data of 46 wells were used as observation points. During the calibration the calculated and measured head data were compared after each modeling run with the different layer parameters, and the procedure was continued until the satisfactory match was obtained.

Figure 4 shows the final result of the trial-end-error calibration process. After the steady-state model calibration, the results were used to build the transient flow model. The hydraulic conductivity distributions were left unchanged for the model layers; the transient flow parameters, such as specific yield and specific storage values, were focused on. Another major point was how to simulate the river, the simulation package of which was to be used as the eastern boundary of the model along the Tisza River. Unfortunately we have no pumping test results along the riverside to be able to calculate the riverbed conductance, the most important parameter in determining the strength of connection between the river and groundwater.
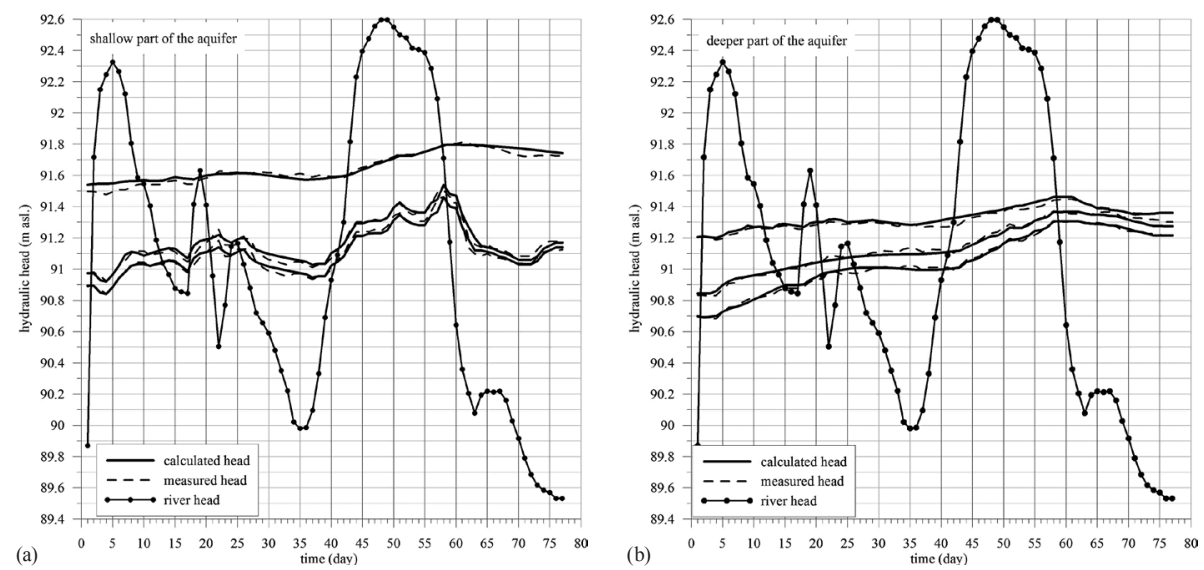

Fig. 5

Fitting results of head time series in shallow (a) and in deeper (b) part of the aquifer 
The magnitude and duration of the leakage between an aquifer and a river is highly sensitive to the nature of the connection and to the difference between the river levels and groundwater levels (Rushton and Tomlinson 1979). This head difference will cause a flow either into or out of the river. The flow mechanism is assumed to be based on Darcy's law, in which the flow rate between the aquifer and river is a direct function of permeability and head difference (Walton 1970). Permeability here means conductance of the riverbed, as in almost all cases there is a clogged zone that weakens the direct communication between the river and the groundwater.

During the numerical computations a linear relationship is assumed between the flow rate and head difference of the aquifer and river. The slope of this linear function is the permeability of the riverbed. This means that with increasing colmation

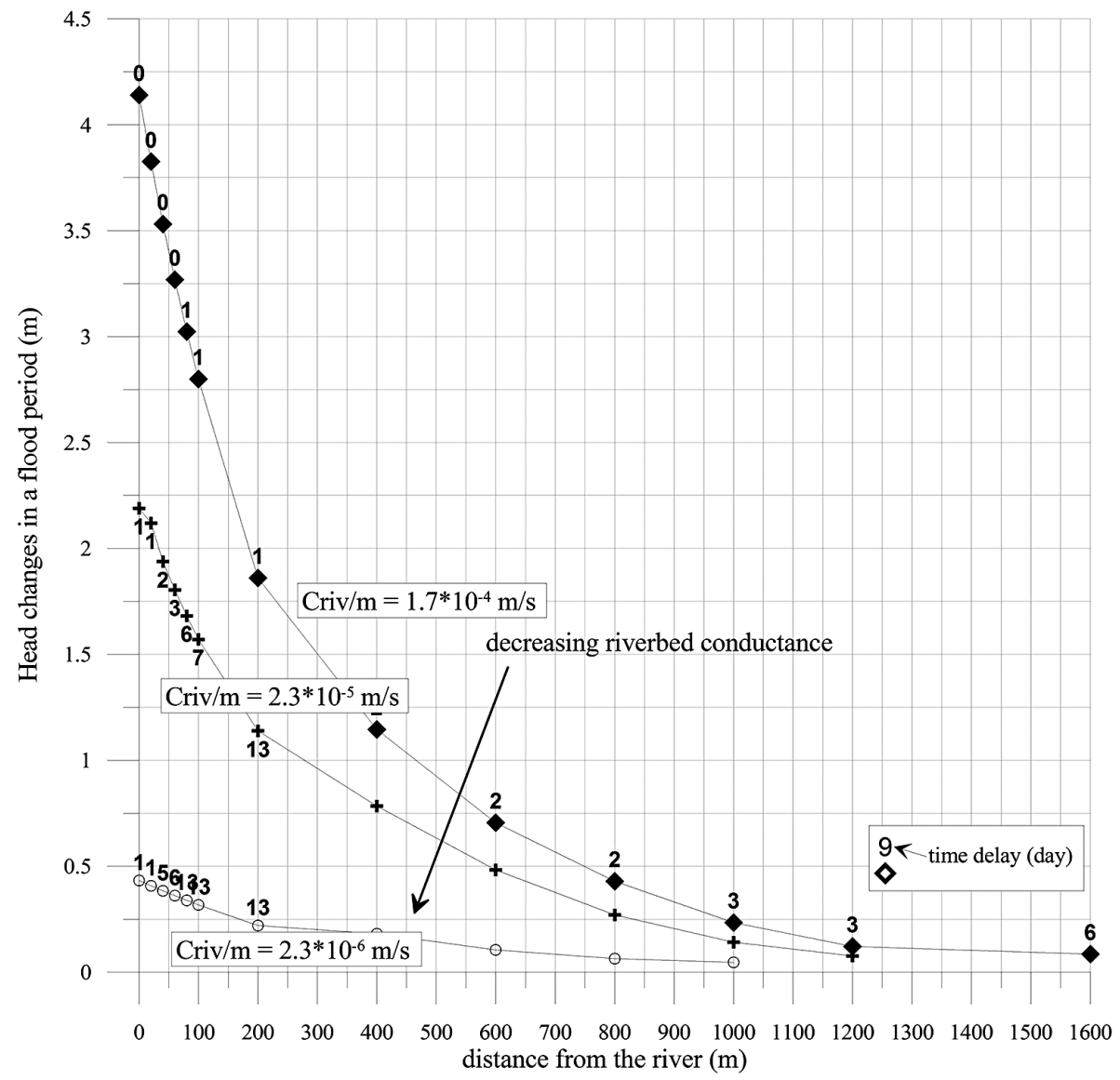

Fig. 6

The calculated maximum groundwater head changes during a flood using different values of riverbed conductance 
the flow velocities as well as the flow rates decrease along with the same head difference between the river and aquifer.

For the calibration we applied the four-year time series of 32 observation points; to begin with we fit the calibrated time series to the measured ones. Figure 5 shows fitted time series of a river flood period. During the fitting procedure the standard error called RMSE was calculated from the difference of the calculated and measured head in each time period. It was found that this error is not very sensitive to changing model parameters. Therefore, in addition to head data in time, we examined other types of measured and modeled parameters and compared them to field results.

Changing the riverbed conductance we calculated the groundwater head differences caused by different flood periods, and determined their dependence upon the distance from the river. These dependencies were created separately for the shallow and deeper part of the aquifer, and the field results were compared to the calculated ones. Figure 6 shows the calculated maximum groundwater head changes during a flood using different values of riverbed conductance.

Another relevant transient parameter is the temporal delay of a flood peak in the groundwater level of wells, and its dependency upon the distance from the river. Since the model has daily time steps in each period, daily delays could be defined for all monitoring points. Although these time values (days) could be determined by getting a better look at the graphical representation of combined groundwater and river level time series, this procedure is very ineffective for more than 30 observation points. Therefore covariance and correlation analysis between the river and groundwater level data were applied to obtain the exact number of days of delay effect.

We calculated the traditional (Pearson-type) linear correlation (Pearson 1896) and the more robust and resistant Spearman-type rank correlation (Spearman 1904) fac-
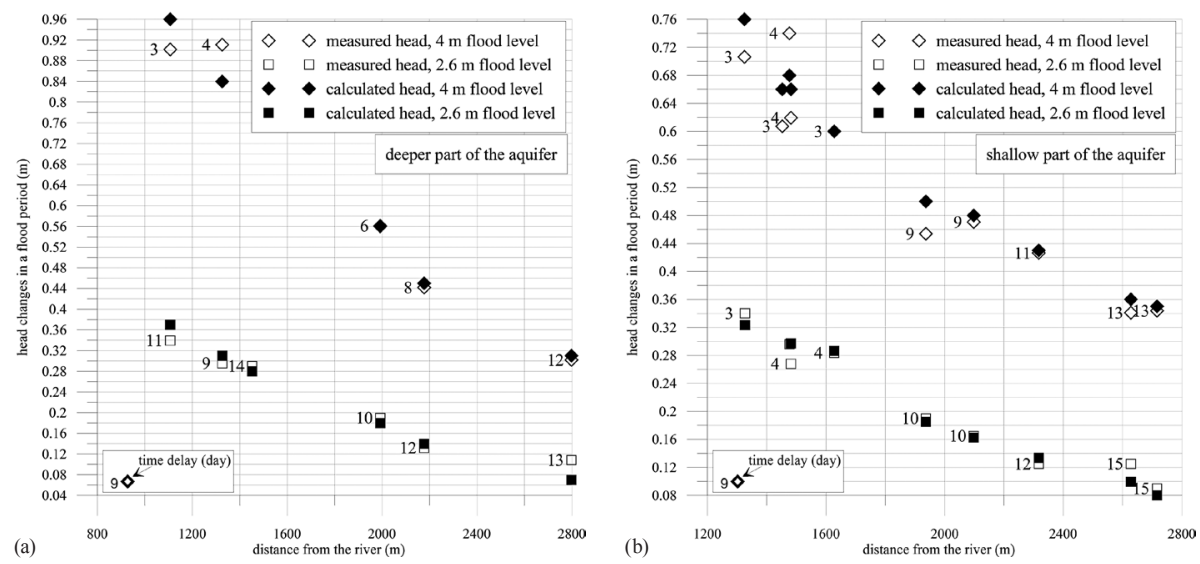

Fig. 7

Measured and calculated groundwater head differences in two flood periods for shallow (a) and for deeper (b) part of the aquifer 
tors for data of the floods' rising periods. The values of covariance and correlation reach their maximum at the delay time. Figure 7 shows the measured and calculated relative groundwater head changing in a flood period at some of the monitoring wells. At 2,000 $\mathrm{m}$ distance from the river there is a more than $10-\mathrm{cm}$ increase in the hydraulic heads. The effect of even a short flood period was already detected both in the shallow and the deeper part of the aquifer, with decreasing pressure changes at increasing distance from the river. In the figure the numbers above the points indicate the day after flood peak of the river when the maximum effect on the groundwater level was recorded. In the homogeneous system, the more distant the monitoring point, the greater the time delay. The few exceptions (see Fig. 7a) are due to inhomogeneities in the aquifer.

During the correlation analysis the relationships between river and groundwater level in floods were visually represented, showing different characteristics for rising and falling stages of the river. Thus the river-groundwater relationship for an unsteady flow will not be a single-value relationship as in a steady flow, but instead be a looped curve. Since the conditions for each flood may be different, different floods may provide different loops.

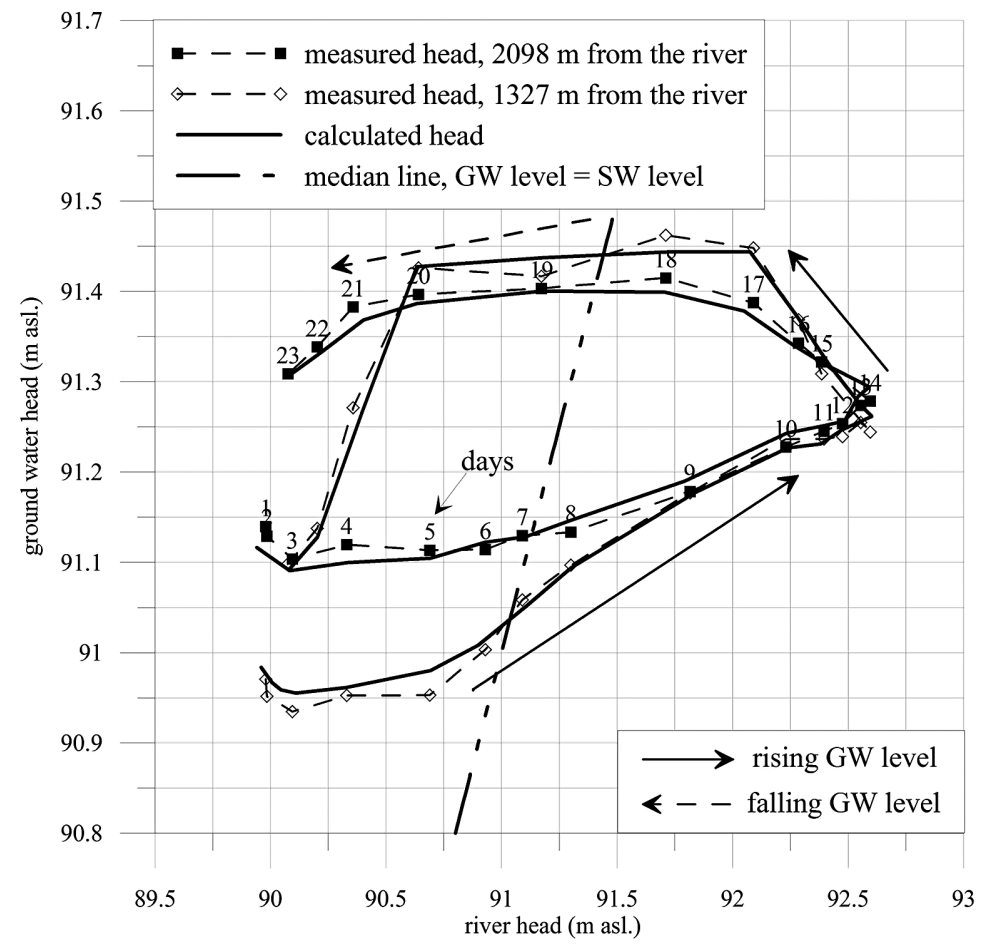

Fig. 8

Flood loop curves for two monitoring wells 
Figure 8 shows the groundwater level for two wells depending on the river level in the case of a spring flood in 2008. These graphs are very similar to the commonly used flood loop rating curve for rivers. The dashed line indicates the median line. If the curve is to left side the dashed line, the groundwater table is higher than the river level; to the right side of the dashed line the flow state is the opposite. The figures show that in the rising river stage the groundwater level is lower than in the falling stage. This means that lower groundwater level is related to the same river level in the rising phase. The time of aquifer replenishment and depletion can be followed. At small distances of the wells from the river depletion begins right after the flood peak. At greater distances the aquifer replenishes after the flood peak and depletion starts later.

Our research showed that for the same well, curve slopes are the same for different floods, but the width of loops and the time when the groundwater level begins to decrease change. At the same time the curves are steeper closer to the river.

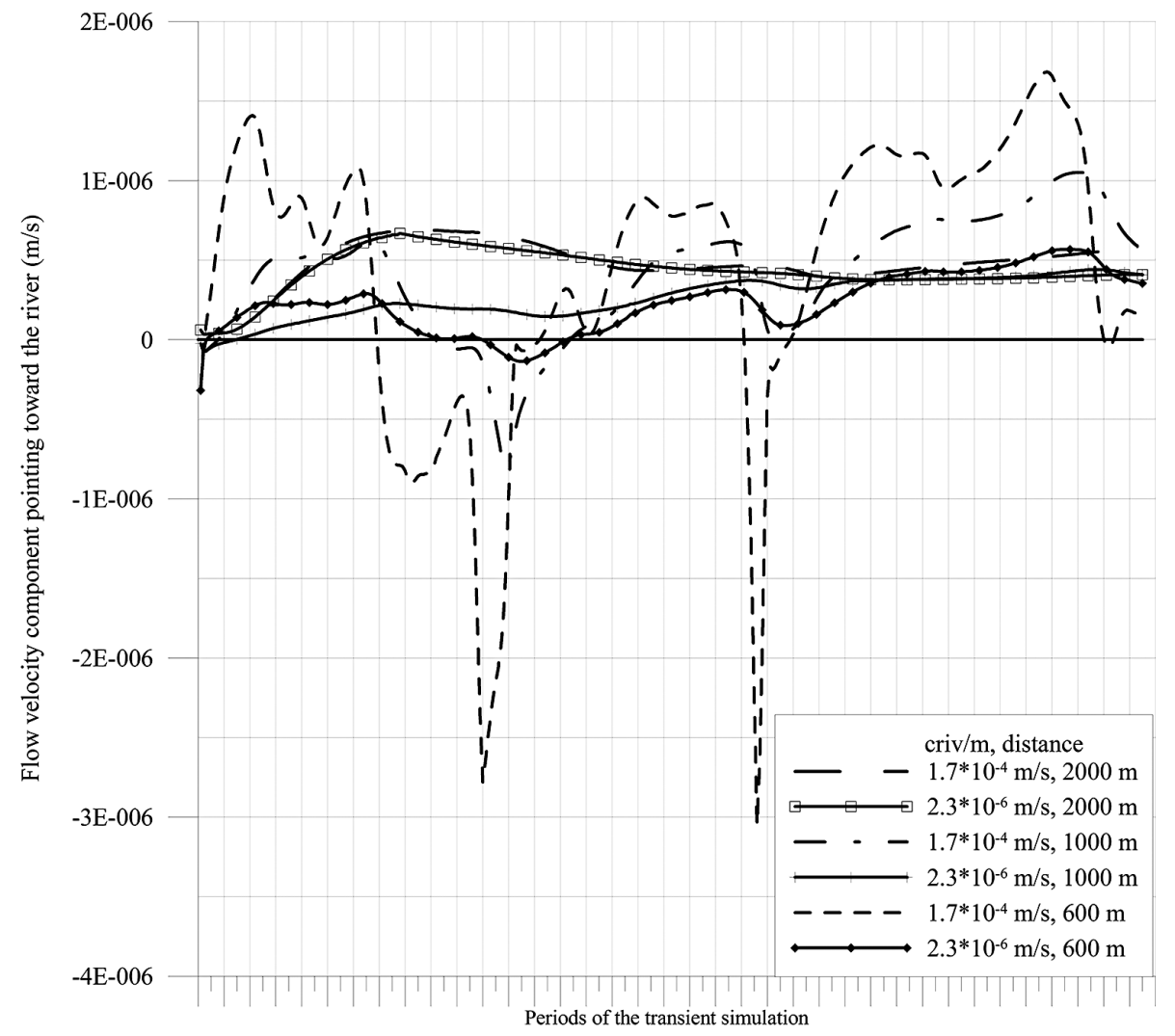

Fig. 9

Flow velocities in time with two strengths of relationship between the river and the aquifer 

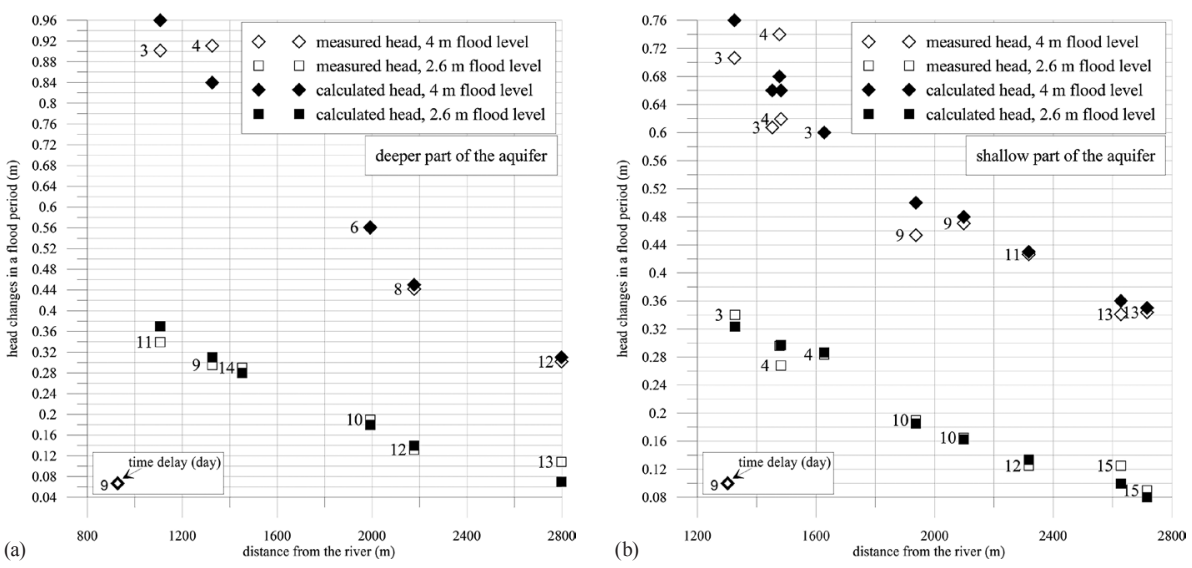

Fig. 10

Flow velocities in distance from the river in a drv (a) and in a flood (b) period of the river

These loop curves were also the basic information used in the calibration process, as they most typically characterize the dynamics of the system. The fitting of calculated loop curves to the measured ones was performed at each monitoring point for different simulated flood periods (Fig. 8). Transient parameters like specific yield and storage of model layers could be precisely determined based on calibration with flood loop curves.

Not only were the groundwater level, head differences, and its relation with the river level analyzed, but the changing flow directions as well. This is important because there are different distances of the river's effect on changes in groundwater level, in flow velocities, and in flow directions. To analyze the effect of the river on flow velocities, a short code was written to calculate the exact seepage velocities in the cells and to determine the distances of changing flow direction in all model periods.

We calculated the seepage velocity distributions using different riverbed conductance values. Figure 9 shows the flow velocities through time in two cases of riverbed colmation. The positive values (above zero) mean that the flow direction is toward the river; negative values are valid for the opposite flow situation. Flow velocity change follows the river level fluctuation, and the effect of changing riverbed colmation for the velocities is presented for up to $2,000 \mathrm{~m}$ from the river. This is the distance at which the two curves run together. Flow velocities at distance for different riverbed conductance and for changing river level were also analyzed. In Fig. 10 the flow velocities calculated for day of a flood peak, and for a day of lowest river level in a dry period, were presented. The results showed that in a flood period the flow velocities change more intensively than in a dry period with river discharge. It can also be concluded that the distance of changing flow directions (when the velocity crosses the zero line) and changing flow velocities (when its value is stabilized) are not the same; these are also different for each simulation period of the model. 
These flow velocity profiles were applied to the calibration in such a way that by increasing the riverbed conductance the above-mentioned distances were determined and compared to field results.

\section{Summary}

A very detailed steady-state and transient flow model with high time-resolution was built to characterize and predict the behavior of an aquifer influenced by the Tisza River. The long-term measurements showed that the dynamic flow pattern is highly influenced by even a short flood period of the river, which confirms the importance of using high resolution flow simulations not only in space but also in time. During the modeling work it was not easy to handle and to calibrate this very complex model.

A multi-step calibration process was performed to increase the accuracy of model parameters as much as possible. It was realized that, while in steady-state flow, the accuracy of the model can be used effectively to compare the measured and calculated head for the observation points, in the case of the transient flow model the comparison of head time series is not enough to permit deciding about the precision of the model. If not only the layer's hydraulic conductivity, but other parameters are also changing variables in modeling, there is a need to support the calibration process from several sides. With this kind of complex calibration, not only were the hydraulic conductivity of the model layers determined, but it became possible to define the transient parameters like specific yield and storage, as well as riverbed conductance, which characterize the strength of the river and aquifer relationship.

In addition to head data through time, head differences at distance from the river taken separately for flood periods, correlation between river and groundwater level, time delays of floods, and flow velocity profiles were applied in the calibration of the transient flow model. In all cases the best fit with the field results was realized changing the flow parameters and the riverbed conductance. All these conditions together were found to be the most suitable tool to determine the different zones of influence, instead of the rather subjective and error-prone evaluation of head time series.

Based on this very accurate flow model, contaminant transport calculations were carried out, the results of which showed a much better accordance with the measurement results than any earlier studies.

\section{Acknowledgements}

The research was carried out in the framework of the Sustainable Resource Management Centre of Excellence at the University of Miskolc, as part of the TÁMOP 4.2.2/A-11/1-KONV-2012-0049 "WELLaHEAD" project within the framework of the New Széchenyi Plan, funded by the European Union and co-financed by the European Social Fund. 


\section{References}

Carrera, J., S.P. Neuman 1986a: Estimation of aquifer parameters under transient and steady state conditions. 1. Maximum likelihood method incorporating prior information. - Water Resources Research 22/2, pp. 199-210.

Carrera, J., S.P. Neuman 1986b: Estimation of aquifer parameters under transient and steady state conditions. 2. Uniqueness, stability and pollution algorithms. - Water Resources Research 22/2, pp. 211-227.

Carrera, J., S.P. Neuman 1986c: Estimation of aquifer parameters under transient and steady state conditions. 3. Application to synthetic and field data. - Water Resources Research 22/2, pp. $228-242$.

Chiang, W.H. 2006: Processing MODFLOW Pro, A Simulation System for Modeling Groundwater Flow and Transport Processes. - Users manual, manuscript, Webtech 360 Inc.

Chiang, W.H. 2010: Processing MODFLOW, An Integrated Modeling Environment for the Simulation of Groundwater Flow, Transport and Reactive Processes. - Users manual, manuscript, Simcore Software.

GÁMA-GEO Ltd. 2008: Evaluation of pumping tests of the industrial site performed during 2007-2008. - Project report, manuscript.

Hill, M.C. 1998: Methods and guidelines for effective model calibration. - U.S. Geological Survey Water-Resources Investigations Report, 98-4005, 91 p.

Hill, M.C., E.R. Banta, A.W. Harbaugh, E.R. Anderman 2000: MODFLOW-2000, The U.S. Geological Survey modular ground-water model - U.S. Geological Survey Open-File Report, 00-184, 209 p.

Marsily, de Gh., J.P. Delhomme, A. Coundrain-Ribstein, A.M. Lavenue 2000: Four decades of inverse problems in hydrogeology. - Geophysical Society of America, Special Paper 348, pp. 1-28.

Pearson, K. 1896: Mathematical contributions to the theory of evolution. III. Regression, heredity, and panmixia. - Philosophical Transactions of the Royal Society, Ser. A, 187, pp. 253-318.

Poeter, E.P., M.C. Hill 1997: Inverse models: a necessary next step in groundwater modeling. - Ground Water, 35/2, pp. 250-260.

Rushton, K.R., L.M. Tomlinson 1979: Possible mechanisms for leakage between aquifers and rivers. Journal of Hydrology, 40/1-2, pp. 49-65.

Spearman, C.E. 1904: The proof and measurement of association between two things. - American Journal of Psychology, 15, pp. 72-101.

Walter, D.A., D.R. Le Blanc 2008: Use of inverse-modeling methods to improve ground-water-model calibration and evaluate model-prediction uncertainty, Camp Edwards, Cape Cod, Massachusetts. U.S. Geological Survey Scientific Investigations Report, 2007-5257, 57 p.

Walton, W.C. 1970: Groundwater Resources Evaluation. - McGraw-Hill, New York, 664 p. 